\section{Commentary: When perfect is not the enemy of good}

\author{
Bahaaldin Alsoufi, MD
}

In the current issue of The Journal of Thoracic and Cardiovascular Surgery, Huang and colleagues ${ }^{1}$ from the Mayo Clinic present their experience with tricuspid valve surgery (repair or replacement) in patients with congenital heart disease who developed lead-induced tricuspid regurgitation. Their cohort was comprised of 54 patients (median age, 48 years) with history of congenital heart disease who received tricuspid valve repair $(\mathrm{n}=30)$ or replacement $(n=24)$. They described the regurgitation as the primary indication for operation, and the determination that it was lead-induced was made either through preoperative imaging or intraoperative inspection. Mortality at 1 month and 5 years was $2 \%$ and $20 \%$, respectively, and was comparable in the repair and replacement groups. Freedom from reoperation was also comparable for the 2 groups. In patients who underwent repair, despite significant early improvement in the degree of regurgitation, it recurred in most of them (nearly $50 \%$ within 1 year and $75 \%$ within 5 years had moderate or severe regurgitation). In comparison, only $10 \%$ of those who received replacement had moderate or severe regurgitation at 5 years, and the indication for late reoperation in the replacement group was mainly for stenosis.

This is an interesting emerging group of patients that is increasingly being tackled because of the expanding population of adults with congenital heart disease. ${ }^{2}$ Tricuspid valve repair has been reported to carry an advantage over

\footnotetext{
From the Department of Cardiovascular and Thoracic Surgery, University of Louisville School of Medicine, Norton Children's Hospital, Louisville, Ky.

Disclosures: The author reported no conflicts of interest.

The Journal policy requires editors and reviewers to disclose conflicts of interest and to decline handling or reviewing manuscripts for which they may have a conflict of interest. The editors and reviewers of this article have no conflicts of interest.

Received for publication Nov 15, 2021; revisions received Nov 15, 2021; accepted for publication Nov 17, 2021; available ahead of print Nov 20, 2021.

Address for reprints: Bahaaldin Alsoufi, MD, Department of Cardiovascular and Thoracic Surgery, University of Louisville School of Medicine, Norton Children's Hospital, 201 Abraham Flexner Way, Suite 1200, Louisville, KY 40202 (E-mail: balsoufi@hotmail.com).

J Thorac Cardiovasc Surg 2022;163:2194-5

$0022-5223 / \$ 36.00$

Copyright (c) 2021 by The American Association for Thoracic Surgery

https://doi.org/10.1016/j.jtcvs.2021.11.028
}
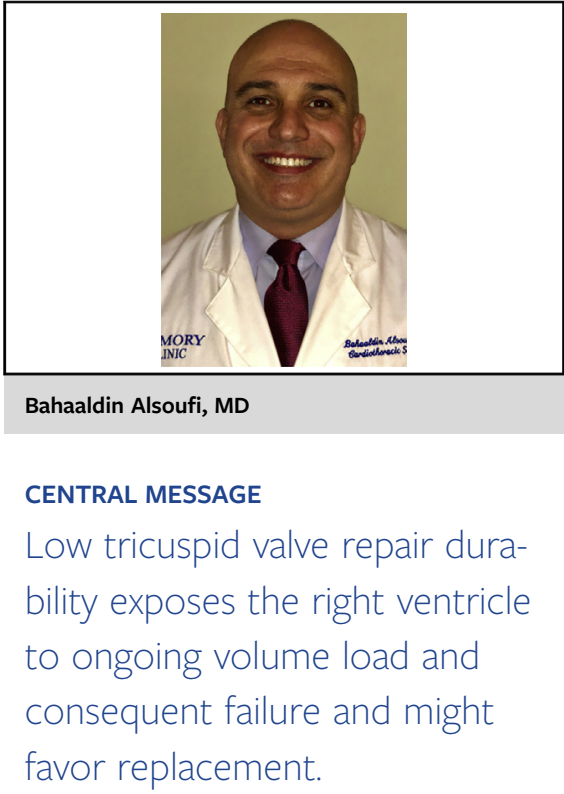

replacement in general; with replacement being associated with higher early mortality rates and shorter long-term survival. ${ }^{3,4}$ However, one has to admit that a repair that is associated with recurrent moderate or severe regurgitation in approximately $50 \%$ at 1 year and $75 \%$ at 5 years is not considered a success, especially because the primary indication for operation in these patients was actually tricuspid regurgitation. The authors do not describe the precise mechanism of failure after repair however, that does not seem to be related to inadequate repair because almost all of their patients left the operating room with mild or less regurgitation. ${ }^{1}$ So basically, the problem is repair durability that seems to be limited in these patients, similar to other groups of patients, especially those with congenital heart disease. ${ }^{5}$

Currently, tricuspid valve replacement is the only alternative to repair that is widely available at our disposal. However, surgeons go to great efforts to avoid replacement because of the associated high operative mortality rate, potential complications, poor late survival, and reoperation need. ${ }^{3,4}$ The right heart in patients with congenital heart disease is particularly challenging, and although elimination of pressure and volume load are important for the long-term health of the right ventricle, the delicate interaction with left heart and pulmonary pathology and preexisting right ventricle dysfunction complicate the decision-making in these patients. Patient selection seems to play an important role in early and late survival and 
those with significant right ventricle dysfunction, pulmonary hypertension, and left-sided pathology are at highest risk for poor survival. ${ }^{3-5}$ My personal feeling is that current indications for tricuspid valve replacement need to be reassessed and in properly selected patients, such as those with lead-induced tricuspid regurgitation, tricuspid valve replacement might be preferable. The arguments that might arise include the following: (1) Is valve replacement associated with exceedingly high operative mortality and poor survival? (2) Does valve replacement complicate future lead extraction in the setting of complications such as endocarditis? (3) Does the need of reoperation expose the patients to a prohibitively high future risk? Reports in the current literature and my personal experience suggest that tricuspid valve replacement in carefully selected patients is associated with acceptable operative mortality and that is again demonstrated in the current series from Mayo. ${ }^{1}$ Although lead entrapment can be an issue and might warrant the need for reoperation in case of endocarditis, we need to acknowledge that this is a very rare occurrence. The authors from Mayo do not report any need for surgical lead extraction in their experience with more than 200 pediatric and adult patients who have undergone tricuspid valve replacement with transvenous lead exclusion between the prosthetic valve sewing ring and the annulus. ${ }^{6}$ Of course, when special concerns arise about future infection, an epicardial lead system at the time of valve replacement is an option. As for future reoperation, although this is definitely an issue, it seems to me that although reoperation was comparable for repair and replacement, there were considerably more patients after repair who were living with significant recurrent regurgitation. When we acknowledge that for tricuspid valve operation or reoperation, the status of the right ventricle is the most important determinant for early and late survival, it becomes obvious that timely reintervention in patients after tricuspid prosthetic failure might be associated with a better preserved right ventricular function and potentially better outcome than in these patients who have been exposed to recurrent regurgitation and associated prolonged volume load, right heart failure, and clinical debilitation. Finally, advances with valvein-valve technology might further favor tricuspid valve replacement over repair that might be inadequate or associated with low durability.

In summary, because of the important interaction between the tricuspid valve and right ventricle, with outcomes of tricuspid valve surgery largely dependent on right ventricle function, a strategy that eliminates chronic pressure and volume load on the right ventricle early on might be preferable. Although tricuspid valve replacement is not perfect by any means, it might be in some patients the superior strategy over nondurable repair.

\section{References}

1. Huang Y, Dearani JA, Lahr BD, Stephens EH, Madhavan M, Cannon BC, et al. Surgical management of transvenous lead-induced tricuspid regurgitation in adult and pediatric patients with congenital heart disease. J Thorac Cardiovasc Surg. 2022;163:2185-93.e4

2. Gilboa SM, Devine OJ, Kucik JE, Oster ME, Riehle-Colarusso T, Nembhard WN, et al. Congenital heart defects in the United States: estimating the magnitude of the affected population in 2010. Circulation. 2016;134:101-9.

3. Choi JW, Jang MJ, Kim KH, Hwang HY. Repair versus replacement for the surgi cal correction of tricuspid regurgitation: a meta-analysis. Eur J Cardiothorac Surg. 2018:53:748-55.

4. Sarris-Michopoulos P, Macias AE, Sarris-Michopoulos C, Woodhouse P, Buitrago D, Salerno TA, et al. Isolated tricuspid valve surgery-repair versus replacement: a meta-analysis. J Card Surg. November 9, 2021; https://doi.org/ 10.1111 jocs. 16131

5. Said SM, Dearani JA, Burkhart HM, Connolly HM, Eidem B, Stensrud PE, et al Management of tricuspid regurgitation in congenital heart disease: is survival better with valve repair? J Thorac Cardiovasc Surg. 2014;147:412-7.

6. Huang Y, Dearani JA, Saran N, Stulak JM, Greason KL, Crestanello JA, et al. Outcomes and echocardiographic follow-up after surgical management of tricuspid regurgitation in patients with transvenous right ventricular leads. Mayo Clin Proc. 2021;96:2133-44. 